\title{
Laparoscopic cholecystectomy under spinal-epidural anesthesia vs. general anaesthesia: a prospective randomised study
}

\author{
Turgut Donmez, Vuslat Muslu Erdem¹, Sinan Uzman², Dogan Yildirim³, Huseyin Avaroglu, Sina Ferahman4, \\ Oguzhan Sunamak ${ }^{5}$
}

Department of General Surgery, Lutfiye Nuri Burat State Hospital, Istanbul, 'Department of Anesthesiology and Reanimation, Lutfiye Nuri Burat Goverment Hospital, Istanbul, Departments of ${ }^{2}$ Anesthesiology and Reanimation, and ${ }^{3}$ General Surgery, Haseki Training and Research Hospital, Istanbul, 'Department of General Surgery, Cerrahpasa Medicine Faculty, Istanbul University, Istanbul, ${ }^{5}$ Department of General Surgery, Haydapasa Numune Training and Research Hospital, Istanbul, Turkey

\begin{abstract}
Purpose: Laparoscopic cholecystectomy (LC) is usually performed under the general anesthesia (GA). Aim of the study is to investigate the availability, safety and side effects of combined spinal/epidural anesthesia (CSEA) and comparison it with GA for LC.

Methods: Forty-nine patients who have a LC plan were included into the study. The patients were randomly divided into GA (n $=25)$ and CSEA $(n=24)$ groups. Intraoperative and postoperative adverse events, postoperative pain levels were compared between groups.

Results: Anesthesia procedures and surgeries for all patients were successfully completed. After the organization of pneumoperitoneum in CSEA group, 3 patients suffered from shoulder pain (12.5\%) and 4 patients suffered from abdominal discomfort $(16.6 \%)$. All these complaints were recovered with IV fentanyl administration. Only 1 patient developed hypotension which is recovered with fluid replacement and no need to use vasopressor treatment. Postoperative shoulder pain was significantly less observed in CSEA group (25\% vs. $60 \%$ ). Incidence of postoperative nausea and vomiting (PONV) was less observed in CSEA group but not statistically significant (4.2\% vs. $20 \%$ ). In the group of CSEA, 3 patients suffered from urinary retention $(12.5 \%)$ and 2 patients suffered from spinal headache $(8.3 \%)$. All postoperative pain parameters except 6th hour, were less observed in CSEA group, less VAS scores and less need to analgesic treatment in CSEA group comparing with GA group.

Conclusion: CSEA can be used safely for laparoscopic cholecystectomies. Less postoperative surgical field pain, shoulder pain and PONV are the advantages of CSEA compared to GA.

[Ann Surg Treat Res 2017;92(3):136-142]
\end{abstract}

Key Words: Laparoscopic cholecystectomy, General anesthesia, Epidural anesthesia, Spinal anesthesia

\section{INTRODUCTION}

Laparoscopic cholecystectomy (LC) is a proven, gold standard surgical procedure for management of gallbladder stones. Early and easily recovery, less hospitalization day and less operative morbidities are the superiorities of laparoscopic cholecystecto- mies comparing with open surgical procedures [1].

Laparoscopic cholecystectomies are usually performed under the general anesthesia (GA) with endotracheal intubation and controlled ventilation. By this way secondary aspiration, abdominal discomfort and respiratory distress due to carbon dioxide pneumoperitoneum could be prevented and avoided from
Received June 20, 2016, Revised August 6, 2016, Accepted October 6, 2016

Corresponding Author: Turgut Donmez Department of General Surgery, Lutfiye Nuri Burat State Hospital, 50. YIl, 2106. Sk. No:8, Sultangazi, İstanbul 34265, Turkey

Tel: +90-5347400967, Fax: +90-212-4764259

E-mail: surgeont73@hotmail.com
Copyright (C) 2017, the Korean Surgical Society

(c) Annals of Surgical Treatment and Research is an Open Access Journal. All articles are distributed under the terms of the Creative Commons Attribution NonCommercial License (http://creativecommons.org/licenses/by-nc/4.0/) which permits unrestricted non-commercial use, distribution, and reproduction in any medium, provided the original work is properly cited. 
hypercapnia [2-5]. First laparoscopic cholecystectomies with spinal and epidural anesthesia were very limited and mostly cases with chronic respiratory disease which have GA contraindication $[6,7]$.

Recent studies about spinal and epidural anesthesia for laparoscopic cholecystectomies verified the safety and availability of this procedure. Regional anesthesia demonstrate less postoperative pain and less neuroendocrine stress response comparing with GA [8-10]. However, abdominal discomfort and shoulder pain are the most frequent complaints [11].

This study is prospective and randomized study which is comparing the combined spinal/epidural anesthesia (CSEA) and GA for laparoscopic cholecystectomies. In this randomized study, we aimed to investigate the availability, safety and side effects of CSEA and comparison it with GA for laparoscopic cholecystectomies.

\section{METHODS}

\section{Study design and patient selection}

In this prospective randomized study, we compared the laparoscopic cholecystectomies with CSEA and GA. The ethics committee approvment (Date/No: December 13 2014/156, Clinical trial number: Clinical Trials gov ID: NCT 02317510) and the informed consent with written and verbal according to Helsinki Declaration were taken. Forty-nine patients of consecutive 67 elective LC patients who have gallbladder stone or polyp operated between December 2014 and May 2015 were included into this study (Fig. 1). Exclusion criterion were: acute pancreatitis, cholangitis, main biliary duct stone, contraindication for spinal anesthesia and pneumoperitoneum, uncooperated patients, psychiatric disease, hemorrhagic diathesis, age lower than 18, American Society of
Anesthesiologists (ASA) physical status classification grade > III, upper abdominal surgery history and pregnancy.

\section{Preoperative evaluation and grouping}

All LC cases were performed by same surgical and anesthesiology team. Patients were divided into 2 group (groups GA and CSEA) randomly with the help of a computer program. Patients in group CSEA were informed by anesthesiologist at the preoperative visit for possible risks such as anxiety, shoulder pain during surgery which could be managed by IV medication or transposition to GA.

\section{Anesthesia procedure}

Premedication did not used for any patient. All patients were prepared for surgery with IV line and $10-\mathrm{mL} / \mathrm{kg}$ ringer lactate solution for 30 minutes. In group GA induction of anesthesia were performed with propofol $(2-2.5 \mathrm{mg} / \mathrm{kg})$, fentanyl $1 \mu \mathrm{g} /$ $\mathrm{kg}$ and rocuronium $0.6 \mathrm{mg} / \mathrm{kg}$ later all patients intubated via endotracheal way. Patients were ventilated with controlled mode $(\mathrm{Vt}=6-8 \mathrm{~mL} / \mathrm{kg}$ ) mechanically. Respiration frequency set as $\mathrm{PETCO}_{2} 32-36 \mathrm{mmHg}$. For maintenance of anesthesia sevoflurane $(1.5 \%-2 \%)$ with the oxygen-air mixture $\left(\mathrm{FiO}_{2}=\right.$ $0.4)$ is used, later on rocuronium $(0.015 \mathrm{mg} / \mathrm{kg})$ is performed with repetitive doses. At the end of the surgery residual neuromuscular block was antagonized with 2- to $2.5-\mathrm{mg}$ neostigmine and 1-mg atropine.

In the group CSEA, anesthesia achieved with needle-throughneedle technique in between the L2-L3 space in a sitting positon at strict sterile conditions. Intradermal lidocaine hydrochloride $1 \%$ was used for local anesthesia. Tuohy 18 -gauge needle was infiltrated into epidural space at midline with saline resistant loss technique. Later on pencil point spinal needle 26 gauge passed through the Tuohy needle and reached

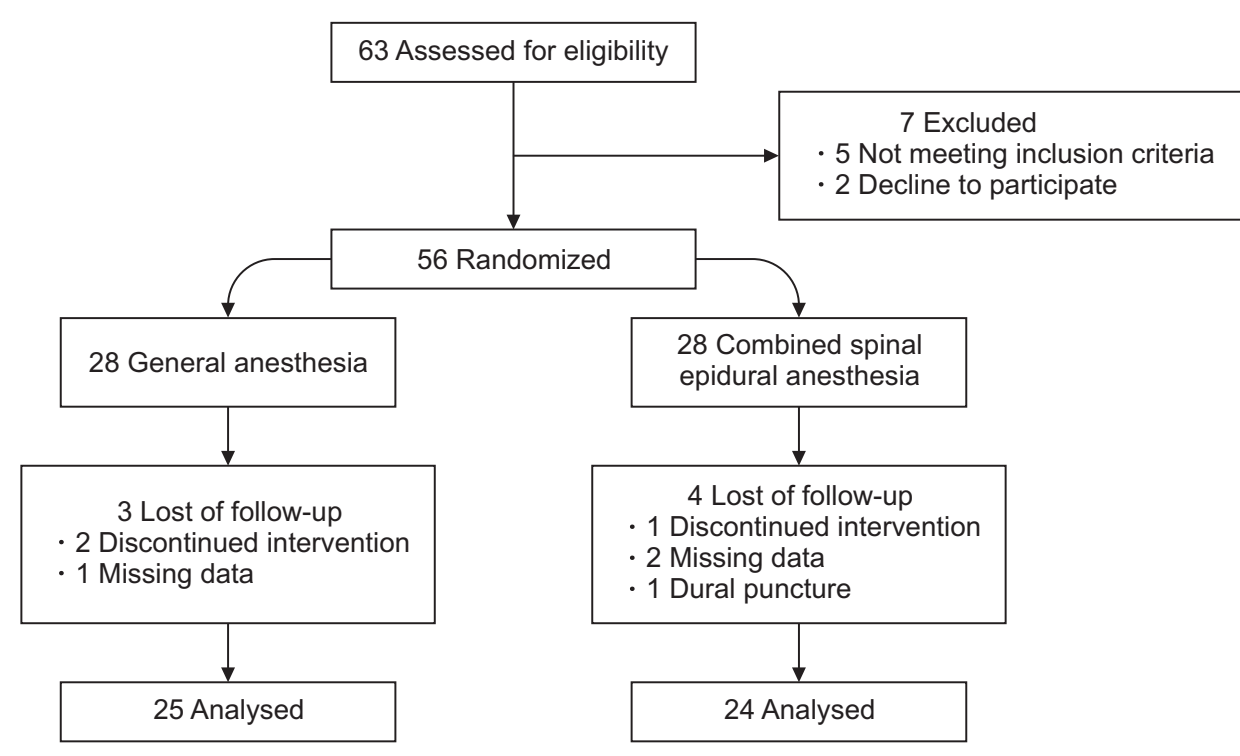

Fig. 1. Flowchart diagram of the study. 
to subarachnoid space. After the observation free leakage of cerebrospinal fluid; hyperbaric bupivacaine $16 \mathrm{mg}$ and fentanyl $10 \mu \mathrm{g}$ were injected for 30 seconds. After all, spinal needle was removed and epidural catheter 20 gauge inserted cephalically and fixed at $4 \mathrm{~cm}$ in epidural space. A mixture with $20-\mathrm{mL}$ volume composed of bupivacaine $0.5 \% 10 \mathrm{~mL}, 2 \%$ lidocaine $5 \mathrm{~mL}$, fentanyl $1 \mathrm{~mL}$ and 4-mL isotonic saline injected into epidural space. Patients positioned with $15^{\circ}$ Trandelenburg position and sensational block level was controlled with pin prick test serially with 1-minute intervals. Surgery was started after the achievement of sensational block at the T4 level. If anesthesia cannot be achieved adequate level or patients cannot tolerate due pain, operation will transpose into the open surgery or GA. In the group, CSEA midazolam $0.015 \mathrm{mg} / \mathrm{kg}$ was used for anxiety and fentanyl 1-2 $\mu \mathrm{g} / \mathrm{kg}$ was used for shoulder pain during the operation.

\section{Surgical procedure}

Pneumoperitoneum was created with $\mathrm{CO}_{2}$ gas by placing a Veress needle followed by placement of a sub umbilical $10-\mathrm{mm}$ port with abdominal pressure maintained at $10 \mathrm{mmHg}$. A $30^{\circ}$ 10-mm laparoscope was passed and the operative difficulty was assessed based on the degree of inflammation, adhesions, condition of gallbladder wall.

The patient was placed in reverse Trendelenburg position and tilted to the left and surgery proceeded as standard procedure. A $10-\mathrm{mm}$ trocar was placed in the epigastrium to the right of the falciform ligament with two additional 5-mm ports in the right upper abdomen 2 finger breadths below the costal margin in midclavicular line and anterior/midaxillary line at the level or just below the umbilicus. Dissection of the gallbladder was performed by the standard technique by first grasping and lifting the fundus, followed by dissection of the cystic duct and artery. Once the 'critical view' of these structures was obtained, these were clipped and divided. The gallbladder was removed from its bed using electrocautery and retrieved through the epigastric port.

\section{Monitorisation and data collection}

All patients monitored with continuous electrocardiography, noninvasive arterial blood pressure and peripheral oxygen saturation $\left(\mathrm{SpO}_{2}\right)$ from entrance to the operation room up to getting to the bed. All monitored parameters, demographic features, ASA, comorbidities, surgery time (time from first incision to last suture) and total time (time from induction of anesthesia or entrance of spinal needle to moving the patient postoperative recovery room) were recovered. Also all cardiopulmonary complications were classified as (1) hypotension ( $>30 \%$ decrease in baseline mean arterial pressure or systolic arterial pressure $<90 \mathrm{mmHg}$ ), (2) bradycardia (heart rate $<50$ beats $/ \mathrm{min})$, (3) hypoxemia $\left(\mathrm{SpO}_{2}<90 \%\right)$ in both groups. In
CSEA group; headache, nausea/vomiting, right shoulder pain, anxiety and abdominal discomfort related with anesthesia and pneumoperitoneum were recorded as intraoperative undesirable situations.

Postoperative pain levels were evaluated with visual analogue scale (VAS; 0 , no pain; 10 , severe pain) at postoperative recovery room, 2nd, 4th, 6th, 12th, 24th hours after the end of surgery by unannounced service nurse. (respectively VASO, VAS2, VAS4, VAS6, VAS12, VAS24). Postoperative situations such as headache, nausea/vomiting, urinary retention, anxiety and abdominal discomfort related with anesthesia and surgery were also recorded. All preoperative and postoperative data were recorded with an observer who is unrelated with anesthesia and surgery team.

\section{Treatment of adverse events}

Patients with hypotension were treated with 250-mL isotonic saline infused in 5-min period. Administration of IV ephedrine $5 \mathrm{mg}$ was considered to the patients who were not responsive to saline treatment or when systolic arterial pressure decreased below $90 \mathrm{mmHg}$. Administration of IV atropine $0.5 \mathrm{mg}$ was also considered for bradycardia.

In the group, CSEA midazolam $0.015 \mathrm{mg} / \mathrm{kg}$ was used for anxiety and fentanyl 1-2 $\mu \mathrm{g} / \mathrm{kg}$ was used for shoulder pain during the operation. All patients had IV fluid replacement with $1 \mathrm{~L}$ ringer lactate and $1 \mathrm{~L}$ isotonic saline within 24 hours. In the need of pain reliever tramadol 50-mg IV infusion within 100$\mathrm{mL}$ isotonic saline for 30 minutes were used. Analgesics were used when VAS $\geq 4$ postoperatively

\section{Statistical analysis}

Statistical analysis was performed by the SPSS ver. 17.0 (SPSS Inc., Chicago, IL, USA). Quantitative variables were expressed as mean \pm standard deviation or median (interquartile range), whereas categorical variables as number of patients and percentage. The normality of quantitative variables was analyzed by Kolmogorov-Smirnov test and normally distributed variables were compared with Student t-test or compared with Mann-Whitney U-test when they did not normally distribute. Categorical variables were compared by chi-square or Fisher exact test. $\mathrm{P}<0.05$ was considered as statistically significant.

\section{RESULTS}

Consecutive 67 elective LC patients who have gallbladder stone or polyp were included into this prospective randomized study. Five patients due to exclusion criteria, 2 patients due to rejection of study, 1 patient due to dural punction during epidural catheter insertion and 6 patients due to follow-up loss were excluded from the study. Forty-nine patients randomly divided into 2 groups as GA $(n=25)$, and CSEA ( $n$ 
= 24), and analyzed (Fig. 1). All patients were discharged at first postoperative day, and controlled at 3rd and 7th day postoperatively. None of the patients encountered any complications.

\section{Patients features}

All patients were diagnosed by hepatobiliary ultrasonography. Forty-four patients were diagnosed as gallbladder stone and 5 were diagnosed as gallbladder polyp. All anesthetisia and surgery procedures were completed successfully and none of the patients need to transpose into open surgery or GA. There was no significant difference between 2 groups for age, sex, body weight, body mass index, ASA physical status classification, and comorbidities (diabetes mellitus, hypertension and chronic obstructive pulmonary disease) (Table 1). Four patients in GA group and 3 patients in CSEA group have 1 coexisting disease. There are 7 patients in GA group and 6 patients in group CSEA which have 2 and more coexisting disease. There was no significant differences between the groups $(\mathrm{P}=0.684)$. Subhepatic drainage was placed in 6 patients in GA group and 5 patients in CSEA group due to minor bleeding from hepatic bed and no significant difference between groups $(\mathrm{P}=0.791)$. All drainages were discharged at first postoperative day.

\section{Procedure related times}

Surgical time was significantly shorter in CSEA group than GA group ( $P=0.042)$. However there was no significant difference in total elapsing time for 2 groups $(\mathrm{P}=0.360$ ) (Table 1 ).

Table 1. Characteristics of the patients

\begin{tabular}{lccc}
\hline \multicolumn{1}{c}{ Characteristic } & GA $(\mathrm{n}=25)$ & CSEA $(\mathrm{n}=24)$ & P-value \\
\hline Age $(\mathrm{yr})$ & $45 \pm 13$ & $45 \pm 14$ & 0.929 \\
Sex, male:female & $18: 7$ & $18: 6$ & 0.812 \\
Weight $(\mathrm{kg})$ & $78 \pm 13$ & $84 \pm 11$ & 0.090 \\
Height $(\mathrm{cm})$ & $164 \pm 8$ & $165 \pm 6$ & 0.750 \\
Body mass index $\left(\mathrm{kg} / \mathrm{m}^{2}\right)$ & $28.75 \pm 4.50$ & $30.63 \pm 3.60$ & 0.113 \\
ASA PS grade & & & \\
$\quad$ I:II:III & $18: 7: 0$ & $16: 6: 2$ & 0.337 \\
Gallbladder disease & & & \\
$\quad$ Stones & $24(96)$ & $20(83.3)$ & \\
$\quad$ Polyp & $1(4)$ & $4(16.6)$ & \\
Coexisting disease & 11 & 9 & 0.644 \\
$\quad$ Diabetes mellitus & 9 & 7 & 0.610 \\
$\quad$ Hypertension & 8 & 6 & 0.588 \\
$\quad$ COPD & 1 & 3 & 0.277 \\
Duration of surgery $(\min )$ & $35(29-48)$ & $30(26-32)$ & 0.042 \\
Total duration (min) & $60(57-71)$ & $60(56-62)$ & 0.360 \\
\hline
\end{tabular}

Values are presented as mean \pm standard deviation, number $(\%)$, or median (interquartile range).

GA, general anesthesia; CSEA, combined spinal/epidural anesthesia; ASA PS, American Society of Anesthesiologists physical status; COPD, chronic obstructive pulmonary disease.

\section{Intraoperative adverse events in group CSEA}

Maximum sensational block was achieved at T3 segment in 20 patients and at T2 segment in 4 patients. None of the patients encountered any respiratory problem. Three patients in group CSEA ( 3 of $24,12.5 \%$ ) suffered from shoulder pain which was managed by $50-\mu \mathrm{g}$ IV fentanyl. Also 4 patients suffered from abdominal discomfort (4 of 24, 16.6\%) during pneumoperitoneum.

All these complaints were managed by IV fentanyl. One patient encountered hypotension which was recovered by short time fluid replacement and no need to vasopressor treatment and also nausea which was controlled by $8 \mathrm{mg} I V$ ondansetron.

\section{Postoperative adverse events}

All adverse events related with anesthesia and surgery were recorded for 24 hours postoperatively. Postoperative shoulder pain was observed in 6 patients in CSEA group (25\%) and 15 patients in GA group (60\%), this difference was significant $(\mathrm{P}=$ 0.013). There was no significant difference between groups for nausea/vomiting, headache, urinary retention and hypotension (Table 2).

\section{Postoperative pain evaluation}

Postoperative VAS levels for both groups were summarized in Table 3. All pain levels were significantly low in CSEA group except postoperative 6th hour. After recording VAS 0 , all

Table 2. Postoperative adverse events

\begin{tabular}{lccr}
\hline $\begin{array}{c}\text { Postoperative } \\
\text { adverse event }\end{array}$ & GA $(\mathrm{n}=25)$ & CSEA $(\mathrm{n}=24)$ & P-value \\
\hline Shoulder pain & $15(60)$ & $6(25.0)$ & 0.013 \\
Nausea/vomiting & $5(20)$ & $1(4.2)$ & 0.189 \\
Urinary retantion & $0(0)$ & $3(12.5)$ & 0.110 \\
Headache & $0(0)$ & $2(8.3)$ & 0.235 \\
Hypotension & $1(4)$ & $1(4.2)$ & $>0.999$ \\
\hline
\end{tabular}

Values are presented as number (\%).

GA, general anesthesia; CSEA, combined spinal/epidural anesthesia.

Table 3. Postoperative pain evaluation

\begin{tabular}{cccr}
\hline Time & GA $(\mathrm{n}=25)$ & CSEA $(\mathrm{n}=24)$ & P-value \\
\hline VAS0 & $8(6-9)$ & $0(0-1)$ & $<0.001$ \\
VAS2 & $7(5-8)$ & $1(0-2)$ & $<0.001$ \\
VAS4 & $6(4-7)$ & $2(1-3)$ & $<0.001$ \\
VAS6 & $4(3-5)$ & $4(3-5)$ & 0.545 \\
VAS12 & $3(2-5)$ & $1(1-2)$ & $<0.001$ \\
VAS24 & $2(1-3)$ & $1(0-1)$ & $<0.001$ \\
\hline
\end{tabular}

Values are presented as median (range).

GA, general anesthesia; CSEA, combined spinal/epidural anesthesia; VAS, visual analogue score. 
patients in group GA required IV 50-mg tradamol infusion for analgesia and a repeat dose after 6 hours. However in CSEA group 13 patients did not require analgesia and only 11 patients required IV 50-mg tradamol infusion between 6 and 9 hours.

\section{DISCUSSION}

This study is a prospective and randomized study which is comparing the CSEA with GA for LC. In this study we showed that CSEA is safe and available method for laparoscopic cholecystectomies and there is no difference from the GA. Also, we showed that CSEA is superior to GA for postoperative pain control. The reason of more effective postoperative pain control for CSEA than GA is the continuous analgesic effect of drugs which are injected to subarachnoid and epidural space. Analgesic requirement in first 24 hour was lower in CSEA group than GA group. None of the patients in CSEA group required analgesic treatment for first 6 hour after the surgery. Postoperative 6th hour VAS levels were equal in both groups but later VAS levels and analgesic requirement were lower in CSEA than GA.

Singh et al. [12] reported in a prospective feasibility study that LC under the CSEA revealed minimal postoperative pain and no requirement for analgesia for first 5 and 6 hours. These findings are similar with us. Two studies comparing the spinal anesthesia and GA for LC Tiwari et al. [8] and Tzovaras et al. [11] reported the better postoperative pain control and lower analgesic requirement in spinal anesthesia than GA due to lasting analgesia effect. In these 2 studies VAS levels at 6th and 8th hours after the surgery (median [range]; 1 [0-4] and 0 [0-6]) were lower than our study. This difference is considered that it could be related with methodological difference between the studies. The difference of the 2 studies from our study is standard postoperative intravenous analgesia and if needed additive opioids usage for patients.

Detected intraoperative adverse events in CSEA group were right shoulder pain and hypotension. Right shoulder pain can be detected during LC under the regional anesthesia. Shoulder pain may be minor with no treatment requirement or may be more severe $[8,11,13]$. Less frequently pain may be more severe and may cause to transpose the procedure to GA $(0.06 \%-10 \%$ of patients) [4-16]. This pain is a referred pain related to irritation of phrenic nerve (C3-C5) which is innervating sensation of lower surface of diaphragm due to carbon dioxide pneumoperitoneum [17]. Incidence of intraoperative right shoulder pain during LC under regional anesthesia range from $4 \%$ to $43 \%$ [8-12]. It is known that for the management of intraoperative shoulder pain; intravenous opioids, subdiaphragmatic local anesthetic aerosolisation, lower pneumoperitoneum pressure during surgery $(<10 \mathrm{mmHg})$ and position change may be helpful and severe pain causing the transposition to GA is rarely occured $[8,9,11-13,15]$. In this study we found the shoulder pain incidence as $12.5 \%$ and the pain was usually recovered with the IV fentanyl easily. None of the patients need to transpose to GA.

In order to perform LC under regional anesthesia sensory block level should be over T6 level [18]. In our study we obtained sensational block up to T2-T3 level which is higher than similar studies. However it is obvious that neuroaxial block level is not the reason of lower shoulder pain incidence due to preservation of cervical roots during the regional anesthesia. This lower incidence may be related with limited pressure $(10 \mathrm{mmHg})$ of pneumoperitoneum and low carbon dioxide insufflation speed. So that lower pneumoperitoneum pressure makes lower shoulder pain statement is verified in our study like other similar studies [19].

In our study cardiovascular changes were at minimal levels. Intraoperatively only one patient suffered from hypotension which is recovered with fluid replacement rather than a vasopressor requirement and none of the patients suffered from bradycardia. In their own case series of Tiwari et al. [8] and Tzovaras et al. [11] reported the hypotension incidence as $4.3 \%$ and 59\%, respectively. Both CSEA and pneumoperitoneum have specific different hemodynamic effects. Regional anesthesia induce hypotension by sympathetic efferent blockage which result with peripheral vasodilatation [20]. Lower pneumoperitoneum pressure in patients with adequate intravascular volume replacement increase the venous return, cardiac output and arterial pressure by decreasing the splanchnic blood volume. Also, sympathetic tonus increment by renin-angiotension-aldosterone system is the neurohumoral mechanism which result with hemodynamic changes after the pneumoperitoenum [21-23]. So that balance with regional sympathetic block and hemodynamic changes caused by light head elevated pneumoperitoneum may explain the lower incidence of hypotension with spinal block level up to T2-T3 which effect all spinal segments responsible for sympathetic outflow. We found that hypotension could be easily recovered with $10-\mathrm{mL} / \mathrm{kg}$ fluid replacement in 15 minutes before the CSEA induction and maintenance of fluid infusion with $6 \mathrm{~mL} / \mathrm{kg}$ during the operation and also lower pneumoperitoneum may prevent the hypotension easily.

The most prominent postoperative undesirable event was significantly higher incidence of shoulder pain at GA group than the CSEA group ( $60 \%$ vs. $25 \%$ ). Postoperatively 6 patients in group CSEA suffered from light shoulder pain which did not require analgesic treatment for a few hours. Three of them had also shoulder pain intraoperatively. In the patients with shoulder pain in group GA analgesic treatment was required and IV tramadol $50 \mathrm{mg}$ was effective for recovery. High incidence of shoulder pain up to $72.5 \%$ in first 24 hour was shown in LC under GA [17]. It is reported that pulmonary recruitment or 
inraperitoneal saline infusion is effective for decreasing the shoulder pain. Postoperative incidence of shoulder pain for spinal and epidural anesthesia was reported as $5.3 \%-16.6 \%$ $[13,24,25]$. Postoperative shoulder pain is explained by phrenic nerve irritation due to residual carbon dioxide similar with intraoperative pain. Reduction in functional residual capacity is higher in GA group patients than the regional anesthesia [26]. Because of the less affected respiratory mechanism carbon dioxide can be more easily eliminated with regional anesthesia, so that this may be the reason for lower incidence of shoulder pain.

Another postoperative undesirable event was nausea and vomiting. Incidence of postoperative nausea and vomiting (PONV) with neuroaxial anesthesia for laparoscopic cholecystectomies was $2 \%-17.3 \%$ however this incidence may be over than $30 \%$ for GA $[12,15,27]$. The incidence of PONV was reported as lower in regional anesthesia than GA but not statistically significant $[11,15]$. This difference was reported as significant in some other studies [27-29]. In our study similarly we found the PONV incidence lower in CSEA group than GA group but not statistically significant. Intravenous ondansetron $8 \mathrm{mg}$ was sufficient for recovery of nausea and vomiting.

Postoperative urinary retention and spinal headache are 2 undesirable events related with regional anesthesia. Urinary retention and urinary catheterization requirement may cause urinary system infection and antibiotic treatment, this may result with longer hospitalization time [11]. The incidence of postoperative urinary retention was reported between $0.41 \%$ and $10 \%[11,12,15,28-30]$. In our study, 3 patients $(12.5 \%)$ suffered from urinary retention in CSEA group. These patients were managed with urinary catheterization and urinary catheter was removed within 2 hours. There was not any complications for urinary catheterization and this did not delay the hospitalization time. It was reported that spinal headache may last up to 2.6 days (mean) and may delay the discharge time with 2.3 days [29]. In our study, 2 patients (8.3\%) suffered from headache related with CSEA similar with other studies. Additional 1-L isotonic saline and tramadol 50-mg infusion was sufficient for treatment and did not delay the discharge time.

In GA group, we found intraabdominal adhesions in 5 patients without prior surgical history. These adhesions caused the longer operation times due to difficulty in laparoscopic surgery in GA group.

In conclusion, as a result, in this study which is one of the first randomized controlled studies comparing the CSEA versus GA for laparoscopic cholecystectomies, we found that CSEA is suitable, sufficient and safe for LC. Also less postoperative pain, and lower shoulder pain and lower nausea/vomiting incidence are the benefits of CSEA compared to GA. Intraoperative adverse events associated with CSEA can be easily treated. However, CSEA may be an alternative to GA in patients who have contraindication or high risk for GA.

\section{CONFLICTS OF INTEREST}

No potential conflict of interest relevant to this article was reported.

\section{REFERENCES}

1. Duncan CB, Riall TS. Evidence-based current surgical practice: calculous gallbladder disease. J Gastrointest Surg 2012; 16:2011-25.

2. Johnson A. Laparoscopic surgery. Lancet 1997;349:631-5.

3. Liu SY, Leighton T, Davis I, Klein S, Lippmann M, Bongard F. Prospective analysis of cardiopulmonary responses to laparoscopic cholecystectomy. J Laparoendosc Surg 1991;1:241-6.

4. Kazama T, Ikeda K, Kato T, Kikura M. Carbon dioxide output in laparoscopic cholecystectomy. Br J Anaesth 1996;76: 530-5.

5. Wittgen CM, Andrus CH, Fitzgerald SD,
Baudendistel LJ, Dahms TE, Kaminski DL. Analysis of the hemodynamic and ventilatory effects of laparoscopic cholecystectomy. Arch Surg 1991;126:997-1000.

6. Pursnani KG, Bazza Y, Calleja M, Mughal MM. Laparoscopic cholecystectomy under epidural anesthesia in patients with chronic respiratory disease. Surg Endosc 1998; 12:1082-4.

7. Gramatica L Jr, Brasesco OE, Mercado Luna A, Martinessi V, Panebianco G, Labaque F, et al. Laparoscopic cholecystectomy performed under regional anesthesia in patients with chronic obstructive pulmonary disease. Surg Endosc 2002;16: 472-5.
8. Tiwari S, Chauhan A, Chaterjee P, Alam MT. Laparoscopic cholecystectomy under spinal anaesthesia: a prospective, randomised study. J Minim Access Surg 2013; 9:65-71.

9. Hajong R, Khariong PD, Baruah AJ, Anand M, Khongwar D. Laparoscopic cholecystectomy under epidural anesthesia: a feasibility study. N Am J Med Sci 2014;6: 566-9.

10. Das W, Bhattacharya S, Ghosh S, Saha S, Mallik S, Pal S. Comparison between general anesthesia and spinal anesthesia in attenuation of stress response in laparoscopic cholecystectomy: a randomized prospective trial. Saudi J Anaesth 
2015:9:184-8.

11. Tzovaras G, Fafoulakis F, Pratsas K, Georgopoulou S, Stamatiou G, Hatzitheofilou C. Spinal vs general anesthesia for laparoscopic cholecystectomy: interim analysis of a controlled randomized trial. Arch Surg 2008:143:497-501.

12. Singh RK, Saini AM, Goel N, Bisht D, Seth A. Major laparoscopic surgery under regional anesthesia: A prospective feasibility study. Med J Armed Forces India 2015;71:126-31.

13. van Zundert AA, Stultiens G, Jakimowicz JJ, Peek D, van der Ham WG, Korsten HH, et al. Laparoscopic cholecystectomy under segmental thoracic spinal anaesthesia: a feasibility study. Br J Anaesth 2007;98:6826.

14. Hamad MA, El-Khattary OA. Laparoscopic cholecystectomy under spinal anesthesia with nitrous oxide pneumoperitoneum: a feasibility study. Surg Endosc 2003;17: 1426-8.

15. Kalaivani V, Pujari VS, R SM, Hiremath BV, Bevinaguddaiah Y. Laparoscopic cholecystectomy under spinal anaesthesia vs. general anaesthesia: a prospective randomised study. J Clin Diagn Res 2014; 8:NC01-4.

16. Kar M, Kar JK, Debnath B. Experience of laparoscopic cholecystectomy under spinal anesthesia with low-pressure pneumoperitoneum: prospective study of 300 cases. Saudi J Gastroenterol 2011;17:203-7.

17. Tsai HW, Chen YJ, Ho CM, Hseu SS, Chao
KC, Tsai SK, et al. Maneuvers to decrease laparoscopy-induced shoulder and upper abdominal pain: a randomized controlled study. Arch Surg 2011;146:1360-6.

18. Lal P, Philips P, Saxena KN, Kajla RK, Chander J, Ramteke VK. Laparoscopic total extraperitoneal (TEP) inguinal hernia repair under epidural anesthesia: a detailed evaluation. Surg Endosc 2007;21: 595-601.

19. Gurusamy KS, Samraj K, Davidson BR. Low pressure versus standard pressure pneumoperitoneum in laparoscopic cholecystectomy. Cochrane Database Syst Rev 2009:(2):CD006930.

20. Toptas M, Uzman S, Isitemiz I, Uludag Yanaral T, Akkoc I, Bican G. A comparison of the effects of hyperbaric and isobaric bupivacaine spinal anesthesia on hemodynamics and heart rate variability. Turk J Med Sci 2014:44:224-31.

21. Gutt CN, Oniu T, Mehrabi A, Schemmer P, Kashfi A, Kraus T, et al. Circulatory and respiratory complications of carbon dioxide insufflation. Dig Surg 2004:21:95105.

22. Cunningham AJ. Anesthetic implications of laparoscopic surgery. Yale J Biol Med 1998;71:551-78.

23. Dexter SP, Vucevic M, Gibson J, McMahon MJ. Hemodynamic consequences of highand low-pressure capnoperitoneum during laparoscopic cholecystectomy. Surg Endosc 1999;13:376-81.

24. Imbelloni LE. Spinal anesthesia for lapar- oscopic cholecystectomy: thoracic vs. lumbar technique. Saudi J Anaesth 2014:8: 477-83.

25. Imbelloni LE, Sant'anna R, Fornasari M, Fialho JC. Laparoscopic cholecystectomy under spinal anesthesia: comparative study between conventional-dose and low-dose hyperbaric bupivacaine. Local Reg Anesth 2011:4:41-6.

26. Bablekos GD, Michaelides SA, Analitis A, Charalabopoulos KA. Effects of laparoscopic cholecystectomy on lung function: a systematic review. World J Gastroenterol 2014;20:17603-17.

27. Mehta PJ, Chavda HR, Wadhwana AP, Porecha MM. Comparative analysis of spinal versus general anesthesia for laparoscopic cholecystectomy: a controlled, prospective, randomized trial. Anesth Essays Res 2010;4:91-5.

28. Bessa SS, Katri KM, Abdel-Salam WN, ElKayal el-SA, Tawfik TA. Spinal versus general anesthesia for day-case laparoscopic cholecystectomy: a prospective randomized study. J Laparoendosc Adv Surg Tech A 2012;22:550-5.

29. Sinha R, Gurwara AK, Gupta SC. Laparoscopic surgery using spinal anesthesia. JSLS 2008;12:133-8.

30. Lee JH, Huh J, Kim DK, Gil JR, Min SW, Han SS. Laparoscopic cholecystectomy under epidural anesthesia: a clinical feasibility study. Korean J Anesthesiol 2010; 59:383-8. 